\title{
Reliability as Main Factor for Future Value Creation
}

\author{
Aleksandras Vytautas Rutkauskas ${ }^{1}$, Viktorija Stasytyte ${ }^{2}$, Andrius Rutkauskas ${ }^{3}$ \\ ${ }^{1,2}$ Department of Finance Engineering, Faculty of Business Management, \\ Vilnius Gediminas Technical University, Vilnius, Lithuania \\ ${ }^{3}$ Laboratory of Business Planning and Environment Economics, Faculty of Business Management, \\ Vilnius Gediminas Technical University, Vilnius, Lithuania

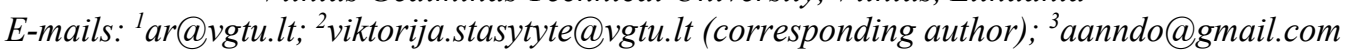

Received 20 February 2017; accepted 10 April 2017

\begin{abstract}
The main objective of the paper is to present the solution to the problem of possibilities' reliability management, which is an important problem of uncertainty (risk) economics. Also, the paper aims to propose adequate methods of stochastic optimization and reveal their broad implementation possibilities. Along with that, the concept of utility function is being disclosed, when we take into account not only the possibilities of prices and costs, but also their reliability, in order to achieve the highest value added in this process. The original methods of stochastic optimization are used, while searching for the optimal allocation of invested capital among the investment assets. Adequate investment portfolio is treated as theoretically sound and practically effective instrument for investment decision-making in capital and currency markets, as well as for other problems related with optimal resource allocation. The adequate portfolio supplements the modern portfolio by adding the third portfolio parameter - the reliability of return. Also, the utility function based on return, reliability and risk is used to find the optimal investment possibility for particular investor. The formed portfolio solutions were tested in the markets of NYSE, UK and France.
\end{abstract}

Keywords: reliability, risk economics, forecasting methods, adequate portfolio.

JEL Classification: C53, C60, P34.

Conference topic: Contemporary Financial Management.

\section{Introduction}

The topics of risk, uncertainty and information have been always crucial in economics (Knight 1921; Hirshleifer, Riley 1992; Ching, Colombo 2014; Iglesias-Casal et al. 2016; Chen et al. 2017). There is no field in economics in which risk is not an important dimension of the decision-making environment (Gollier 2001; Taleb 2010; Chen, Zhang 2014; Rudzkis 2014; Jankauskas et al. 2014; Zeng et al. 2017). There is a small amount of decisions that can be taken in the situation of complete certainty. The majority of economic events take place in circumstances in which economic decisions must be made without complete knowledge about current or future conditions (Machina, Viscusi 2014). These decisions involve financial forecasting (Samonas 2015; Stadnik et al. 2016), rational allocation of scarce resources (Fang, Li 2015; Boukherroub et al. 2017), achieving the value added in various fields of activity (Duval et al. 2016). To solve these problems, the methods of stochastic optimization are often used (Bruni et al. 2017; Song et al. 2017). Uncertain variables are treated as probability distributions, their density, accumulated distribution and survival functions are sources of information for decision-making (Aven 2008). The utility function is applied to select an optimal solution (Rutkauskas, Stasytytė 2008).

The object of the research is activities that require costs and generate results. These costs as well as results are quantitatively measurable, and also can be interrelated by quantitative dependencies. The obtained results are presented as insightful probability distributions of the projected indicator. The original stochastic optimization methodology is used for decision search. The main objective of the paper is to present the application scheme of the contents of reliability category that is objectively formed to foster the future value. It is worth noticing that the contents of reliability category (Rutkauskas, Stasytyte 2011a; Rutkauskas, Ostapenko 2016) is by its essence the reliability of possibility of the stochastic value that is measured by the traditional expression of probability: $P(x)=p\{\xi>x\}$. Along with that, the methods attributed to the field of reliability engineering, originally developed by the authors, will be demonstrated.

In the first part "Fostering the future value" of the paper the scheme of determination of future value for the selected asset was conceptually created and experimentally used. The second part "Reliability as a factor of investment

(C) 2017 A. V. Rutkauskas, V. Stasytyte, A. Rutkauskas. Published by VGTU Press. This is an open-access article distributed under the terms of the Creative Commons Attribution (CC BY 4.0) License, which permits unrestricted use, distribution, and reproduction in any medium, provided the original author and source are credited. 
portfolio return possibilities" of the paper describes the particular attempt of the authors to adapt the previously developed scheme for investment portfolio formation and practical application in financial markets. The initial question to answer was whether the idea about the existence of the optimal composition of possibilities, their reliability and riskiness that is embedded into the future value estimation algorithm provides the algorithm with the status of insightful investor. This would allow the investor to create the maximum utility in every situation. The third part is properly illustrated with practical application examples of investment portfolios created by the authors that are applied in various financial markets.

The methods used in the paper are stochastic optimization, adequate portfolio model, modeling, graphical analysis.

\section{Fostering the future value}

When you pose a question, what will be the value of the selected asset in the future, you receive the answer, or you can check it in a manual and clearly find the answer. It is enough to use the algorithm that links the present value of an asset or any performed action, and you can see the nominal value in the future of the asset under analysis.

However, we should understand that such answer is not informative, because it contains the word nominal (certain, some). Thus we remain not satisfied with the answer and our curiosity persists. Soberly thinking, the analysed value can completely diminish, or it can grow substantially. We can look constructively to the developing situation using the dependency of the Future Value on the Present Value, as well as its growth rate $(S)$ during the certain time period $(n)$ :

$$
F V=P V(1+S)^{n}
$$

where: $F V$ - future value; $P V$ - present value; $S$-growth rate (interest rate); $n$ - time period (number of years).

The view is obvious, but only till we remind ourselves that the growth rate for the perspective cannot be reasoned in determined terms, even in the short-term period. If we watch the value growth process purposefully, we will gather data to evaluate the growth rate as a stochastic variable. The systematic statistical observation data usually is used for this purpose. Even if there are no statistical data, we can use the principles of stochastically informative expertise in order to form the probabilities under investigation.

Let us assume that we have used all the possibilities described above and have determined that under the analysed situation the value growth rate can be precisely enough described using the Triangle distribution, the Probability Density Function $(P D F)$ of which is defined as follows:

$$
P D F= \begin{cases}0, & \text { for } x<a, \\ \frac{2(x-a)}{(b-a)(c-a)}, & \text { for } a \leq x<c, \\ \frac{2}{b-a}, & \text { for } x=c, \\ \frac{2(b-a)}{(b-a)(b-c)}, & \text { for } c<x \leq b, \\ 0, & \text { for } b<x .\end{cases}
$$

where $a, b$ and $c$ are statistical parameters: $a: \in(-\infty, \infty) ; b: a<b ; c: a \leq c \leq b ; x-$ a possible value of the analysed random variable.

In literature on statistics you can find information on the (2) function and the contents and practical use of other distribution functions $f(x), F(x)$ ir $R(x)$. In our case $a$ should serve as the lowest limit of the Future Value possibilities, $b$ - the analogous highest limit, and $c$ - the most expected value of possibilities.

To perceive the situation more particularly and in details, let us look to the specific situation, when it is estimated that $a=0,03, b=0,07$ in all cases, while $c$ can take three options: first - when $c$ is close to $a$, second - when $c$ is close to $b$, and third - when $c=(a+b) / 2$.

The initial value equals 100 , and the time period is $n=5$. After performing valuations, we place them into Figures 1, 2, 3 and 4. We can see from the figures that there are different situations. In the first case the most expected value of the Future Value substantially lags the mean value, in the second case it outpaces the mean value, and in the third case these values almost coincide.

However, Figures 1-4 present not only the possibilities of the passive watch, but also the assumptions for thinking, that there is a need to create possibilities to manage the structure of the probability distribution, devoting the main efforts to the increase of the most expected value of possibilities. In practise such possibilities are being formed naturally - in investment portfolio formation out of assets having different probability distributions, in allocation of the produced product among the three realization markets, etc. In our case the experiment would be a task to allocate the initial value among the three Future Value fostering possibilities that were mentioned above in order to obtain the highest growth of the Future Value in general. 


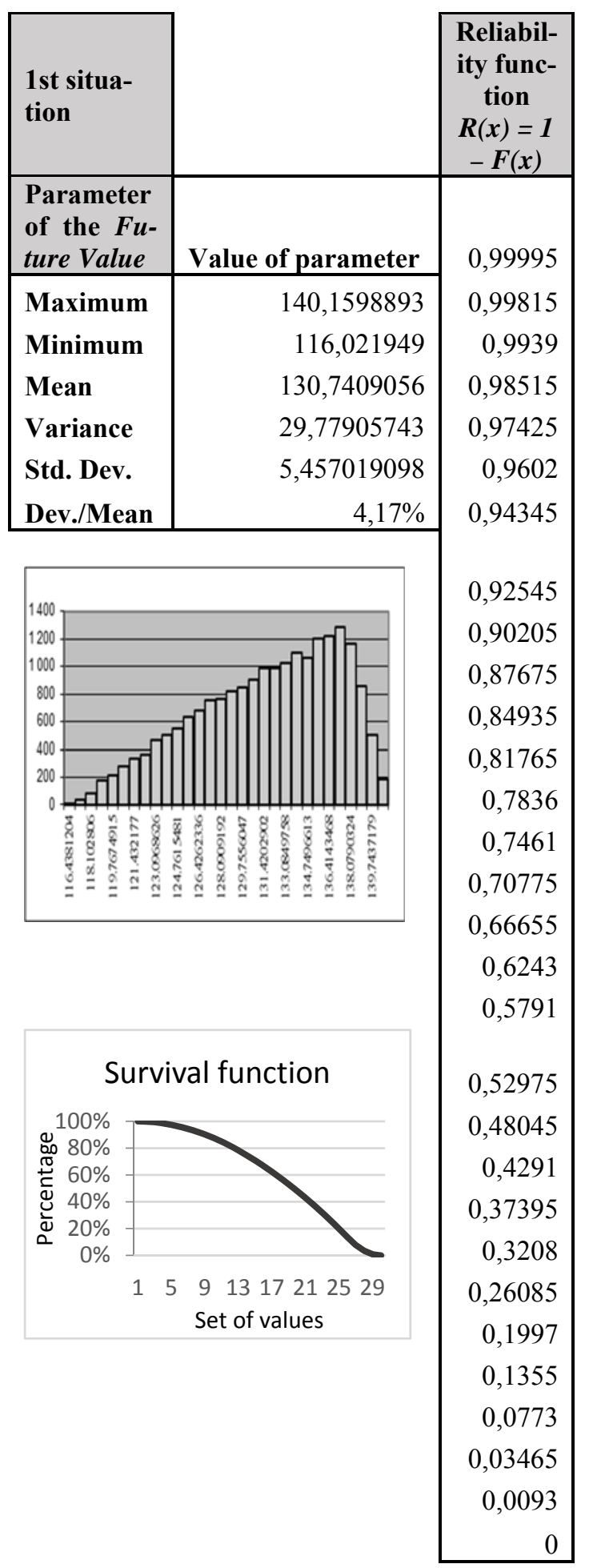

Fig. 1. The detailed view of the probability distribution of the Future Value possibilities, when the probability distribution of the growth rate is right-skewed

(Source: compiled by the authors, based on research results)

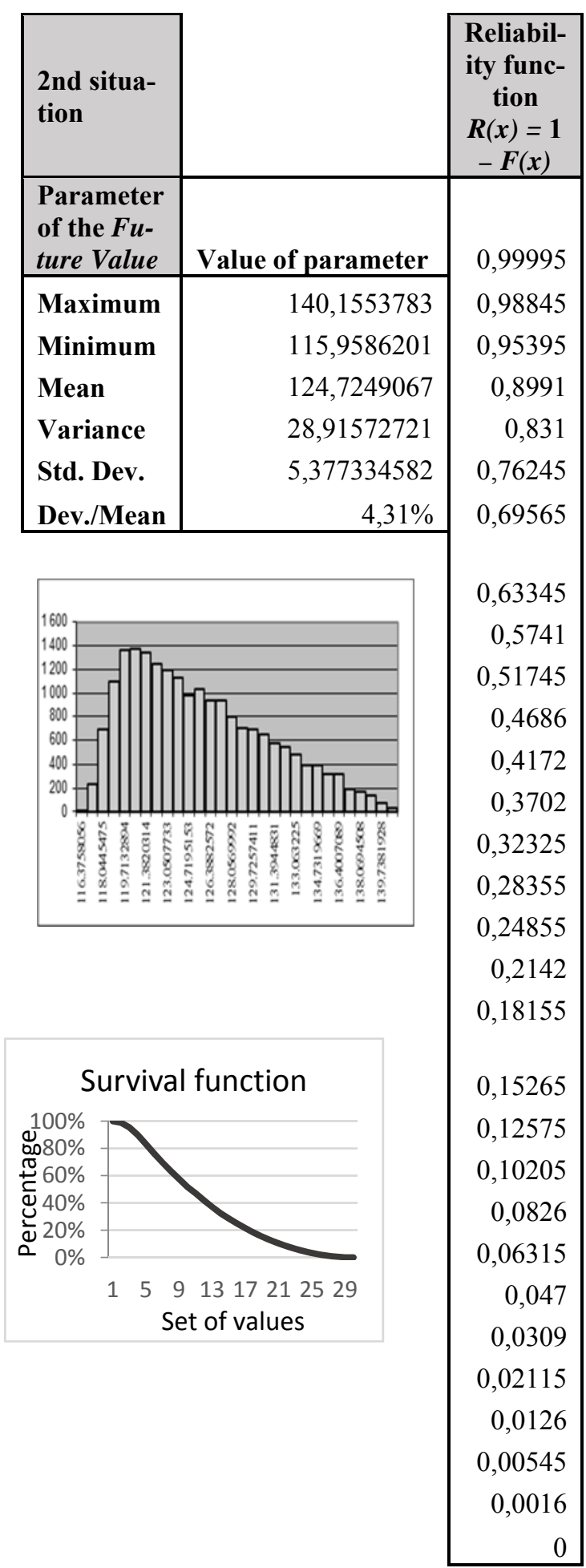

Fig. 2. The detailed view of the probability distribution of the Future Value possibilities, when the probability distribution of the growth rate is left-skewed

(Source: compiled by the authors, based on research results) 


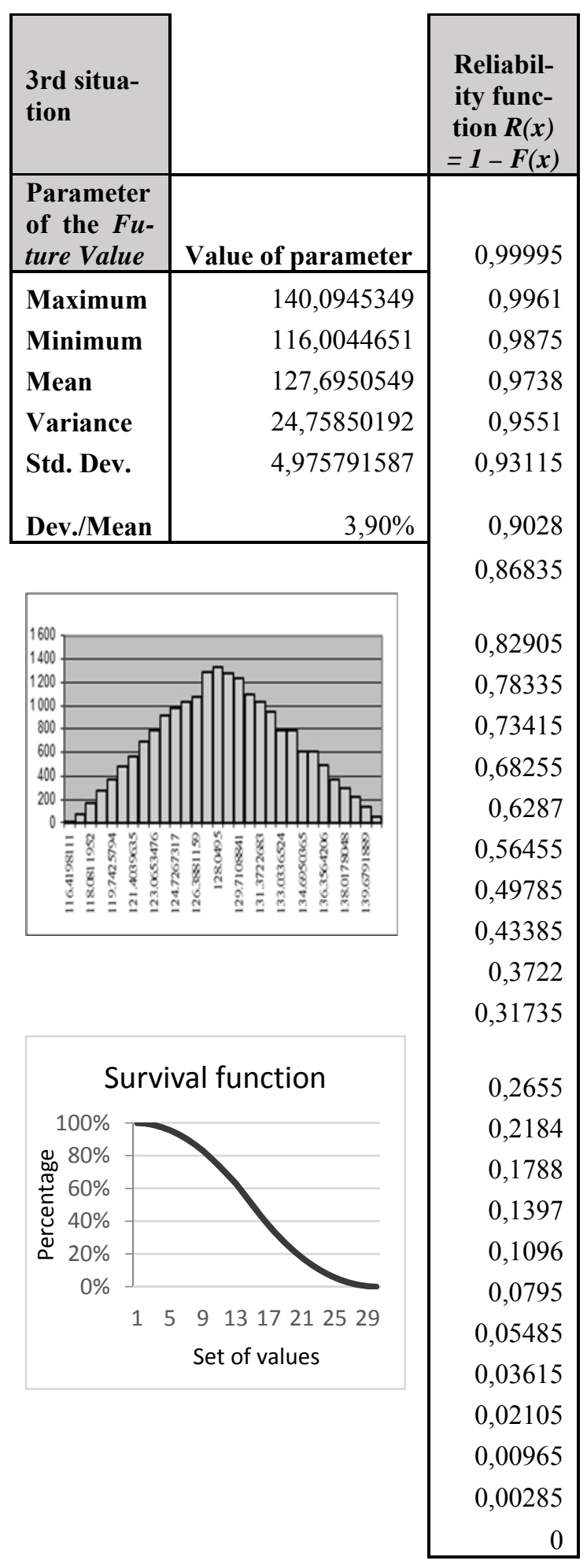

Fig. 3. The detailed view of the probability distribution of the Future Value possibilities, when the probability distribution of the growth rate is centred

(Source: compiled by the authors, based on research results)

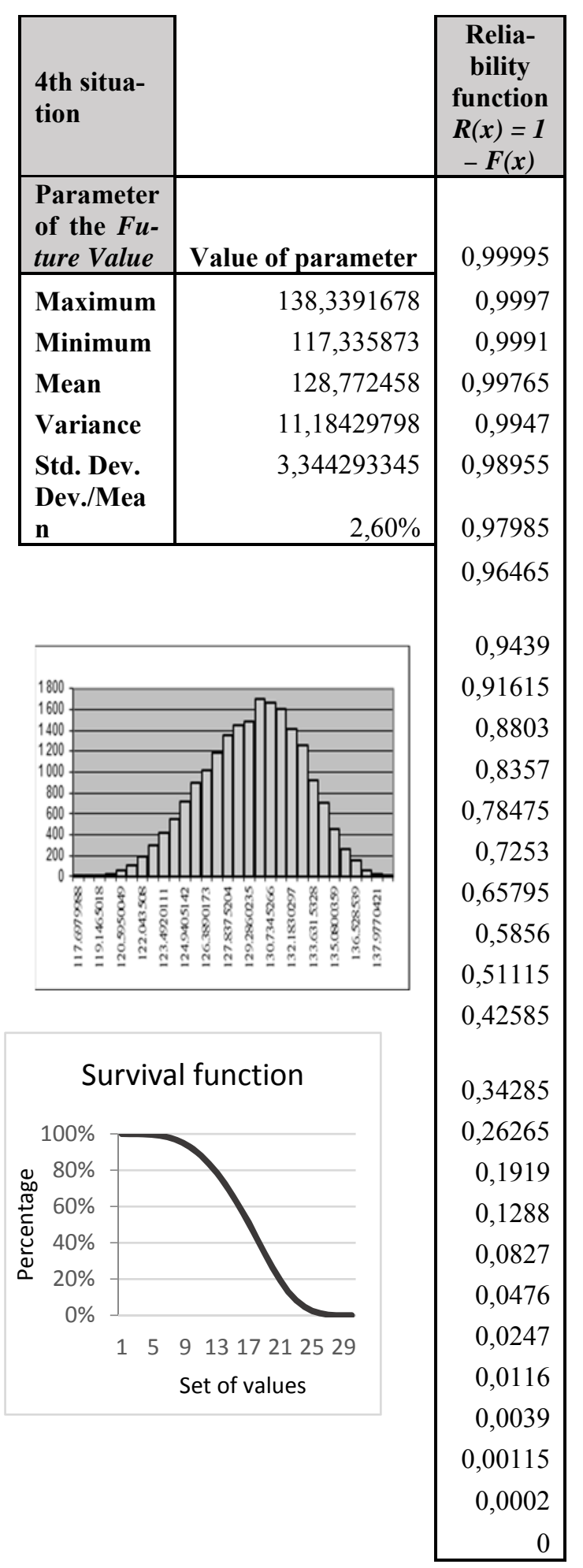

Fig. 4. The detailed view of the optimal solution of the probability distribution of the Future Value possibilities (Source: compiled by the authors, based on research results) 
Such tasks are usually solved by maximizing the adequately formed utility function (Rutkauskas, Stasytyte 2008, 2011; Rutkauskas et al. 2014; Rutkauskas, Ostapenko 2016).

We select the traditional utility function:

$$
N=\frac{R_{x} \cdot p_{x}}{r_{x}},
$$

where: $R_{x}$ - the value of the possibility; $p_{x}-$ the reliability of the value; $r_{x}$. - the level of riskiness of the value.

Using the program of stochastic optimization we obtain that the possessed volume of the Present Value should be allocated according the following proportions among the three assets fostering the Future Value: $\mathrm{w}_{1}=0,495, \mathrm{w}_{2}=$ $0,195, \mathrm{w}_{3}=0,33$. Thus we obtain the highest value of utility function. The detailed explanation of the decision process will be presented in the next part of the paper.

The solution itself is presented in Figure 4. Is the optimal solution good enough? Unfortunately, the unambiguous answer to our selected allocation of resources among the three assets will reveal only after five years. But in reality there are many situations where such assessments and estimations are the only possible ways.

The efficiency of such decisions can be quickly enough assessed for example in exchange or capital markets, where everyday closing prices are being fixed. Decision making with regard to the reliability of possibilities in financial markets is presented in the next part of the paper.

The ratios retaining the long-term stability, such as mean, mode and standard deviation, indicate the advantages of the optimal solution presented in Figure 4, comparing to cases showed in Figure 1 - Figure 3.

More precisely, Figures 1-4 present the result of the simulation of the Future Vale, according the (1) formula, when the probability distrinution of the growth rate $S$ has different forms:

Figure $1\left(1^{\text {st }}\right.$ situation $)$ - the probability distribution of the growth rate $S$ is right-skewed;

Figure 2 ( $2^{\text {nd }}$ situation $)$ - the probability distribution of the growth rate $S$ is left-skewed;

Figure $3\left(3^{\text {rd }}\right.$ situation $)$ - the probability distribution of the growth rate $S$ is centred;

Figure $4\left(4^{\text {th }}\right.$ situation $)$ - the probability distribution of the growth rate $S$ is optimized.

Along with the graphical views, in Figures 1-4 the statistical parameters of the Future Value are presented (minimum, maximum, mean value, variance, standard deviation and deviation from mean value in percentage (also called the coefficient of variation)). The last column in each figure shows the reliability function $\left(R_{x}\right)$, calculated as "1 accumulated distribution function", which will be defined in details in formula (4).

In the next part "Reliability as a factor of investment portfolio return possibilities" we will continue the introduction and the topic initiated in Chapter 1 about the application of reliability of stochastic value possibility to increase the portfolio value, including reliability into the utility function describing the optimal solution. The distinctive provision in this case is that we will be able to assess the insight of the solution immediately, or just depending on the trading regulation in the market.

\section{Reliability as a factor of investment portfolio return possibilities}

The investment portfolio as a system whose components are various asset classes and whose main function is to generate such a set of investment return opportunities that best serves the interests of a particular investor. It means that it regards the advantageous composition of investment rate of return and risk for the investor, i.e. the efficiency of investment.

Efficiency of investment return is a crucial guarantee for successful development of business unit, region or country. To discover the increase of investment return opportunities, the most prominent Nobel Prize scientific works are imposed (Fama 1991; Campbell, Shiller 2007). However, it should be noted that a considerable part of analytical works about investment return opportunities reveal and implement relationships between portfolio return potential and risk of portfolio assets, measured by the standard deviation or a certain deviation function. Meanwhile, reliability should become the prompter measure to reveal the portfolio return possibilities (Rutkauskas 2006). Moreover, a number of activities for constructive perception of reliability as an economic factor require greater consideration. True, both concepts of investment return and reliability are used in very different classes of portfolios and activities. It signals a complexity of monosemantic application of these concepts (Rutakauskas et al. 2014; Lapinskaite, Rutkauskas 2013; Rutkauskas, Stasytyte 2013). The anatomy of investment portfolio allows to adequately understanding not only the content of reliability, but also the opportunity of its numerical value to serve as the factor of investment return.

We are going to use the assumption that to describe the investment portfolio return possibility, one can identify the adequate probability distribution of possibilities. It can be assessed using the historical data of return of the selected assets or with the help of expert valuations. This means that for each asset there are three unambiguously characterized functions:

$$
\begin{gathered}
f(x)=p(X=x)-\text { density function, } \\
F(x)=p(X<=x)-\text { distribution function, } \\
R(x)=1-F(x)-\text { reliability function, or survival function, }
\end{gathered}
$$


where: $f(x), F(x), R(x)$ - functions; $X$ - the analysed stochastic variable; $x$ - the set of possibilities of the stochastic value; $p$ - probability, ex. $p(X=x)$.

To simplify the understanding, let us suppose that we will examine discrete random variables or their distributions, or approximations of continuous distributions using discrete distributions. This means that for continuous distribution describing a set of possibilities of assets it is possible to choose a sequence of real numbers:

$$
x_{1}, x_{2}, x_{3}, \ldots, x_{n-1}, x_{n}
$$

They will approximate the functions of the analysed asset as the three functions in Eqn (4). Number $n$ can always be selected such that it would be sufficient for each of the portfolio assets to approximate with the desired accuracy its continuous distribution.

We can form a portfolio from assets, composing it as just a weighted sum of assets or performing other steps which satisfy the requirements for actions with real numbers and do not preclude the possibility to create portfolio distribution functions based on asset distributions. Thus it is always possible to get the desired amount of portfolios $y_{j}, j=\overline{1, m}$ and reliability functions that naturally form inside these portfolios. These portfolios would have different return reliability structures $R_{j}^{\eta j}, j=\overline{1, m}$ row.

$$
\begin{gathered}
y_{1}, y_{2}, y_{3}, \ldots, y_{m} ; \\
R_{1}^{\eta 1}, R_{2}^{\eta 2}, R_{3}^{\eta 3}, \ldots, R_{m}^{\eta m},
\end{gathered}
$$

where: $y$ - possible portfolios; $R$ - return reliability structure.

(6) formula is a peculiar scorecard, which includes the opportunity set of portfolio return and the accompanying set of reliability functions. This line of pairs can be sufficient for an investor to conceptually decide which pair, i.e. which composition of return and reliability is the most appropriate.

The last statement has to attain for a more detailed explanation. According to the classic understanding of portfolio, investment portfolio is taken as some of the investor's assets contained as the investor's property and managed for a specific purpose. As a required attribute of complete understanding of portfolio possibilities a structure of portfolio can be used. This structure indicates what portion of the portfolio value is assigned for individual assets. The assets in the portfolio mainly are perceived as stochastic values. And yet, the exclusive attribute of classic portfolio is assumed that the portfolio is simply the set of assets. Analytically, this means that the portfolio is total assets, it means the sum of stochastic values. So, analytically portfolio is a stochastic value, its trajectory in time - random process, its trajectory according any random variable parameter - random field (Rutkauskas, Stasytyte 2011b).

Perhaps the most popular researches are about portfolios of financial assets. There are created new methods of searching for investment opportunities and generation of effective solutions (Zopounidis et al. 1997; Campanale et al. 2015). The most prominent Nobel Prize scientific works analyse a new ideology of investment, considering the riskiness of investment assets and, therefore, the riskskiness of the investment space itself.

However, the ideology of investment portfolio develops not only in the direction of financial assets, but also for projects of different activities, for different allies in different unions, for different circle of friends, and so on. All of these are "portfolio" diversity (Bessler, Wolff 2015).

It is understood that investment resources, forms of return and purposes are becoming more diverse, along with that analytical methods of the management of investment portfolios also change rapidly (Steuer, Na 2003). However, extremely complex requirements arise for portfolio management when we have a portfolio of asset functions. Naturally, such situation arises also in the case of financial assets, for example, when we are dealing with portfolios of derivatives and the like (Martinkute-Kaulienè 2014).

The adequate portfolio is a means for investment decision-making with regard to reliability of return possibilities (Rutkauskas 2006; Rutkauskas, Stasytyte 2011a). The expression of investment return using three parameters previously defined - efficiency, reliability and risk - offers an original way to individually orient towards the possibility of return generated by the portfolio. This is opposed to the usual way of considering only the mean or the most expected value of the probability distribution (set).

Figure 5 shows the possibilities of return (possible values of the random variable) that could be generated by the particular portfolio with regard to the stochasticity of investment assets return. Along with that, the three-dimensional view of the utility function is presented; this function can be used for investment strategy formation in order to satisfy the investor's interests. 


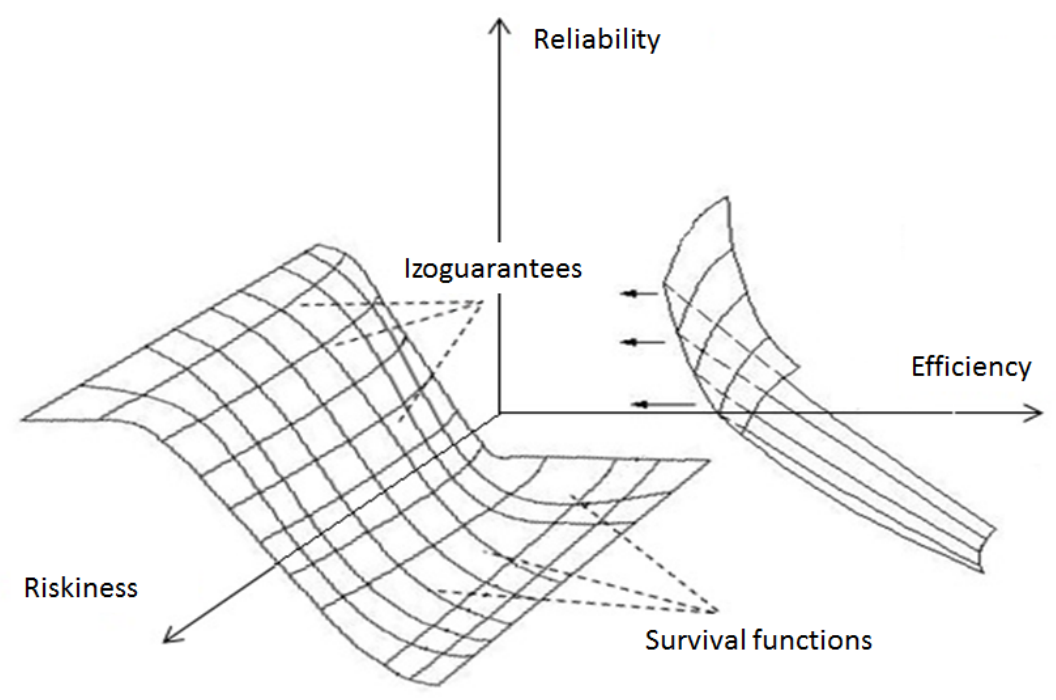

Fig. 5. The surface of reliability functions of the adequate portfolio and the corresponding utility function (Source: compiled by the authors)

Of course, in order to reach the adequate investment strategy for investor's interests one should invoke versatile possibilities of adequate investment portfolio (Fig. 6).

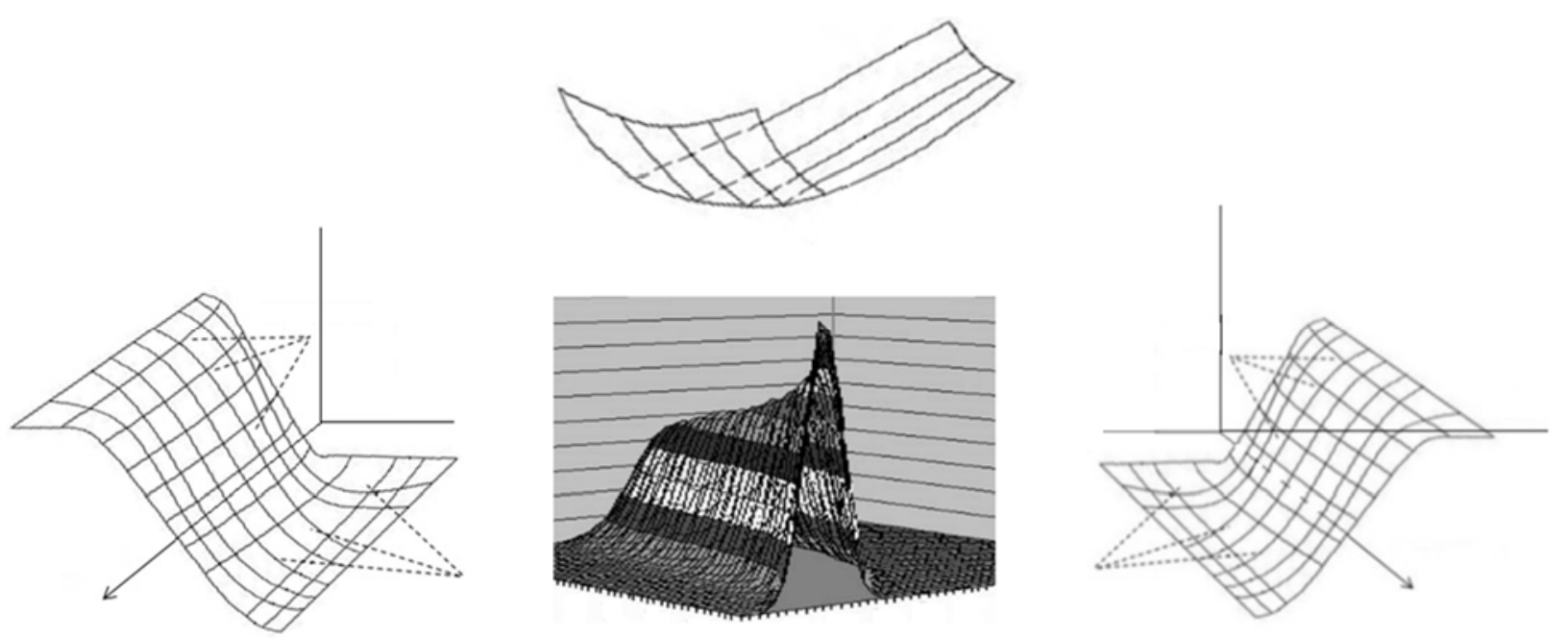

Fig. 6. The complete image of opportunities of adequate portfolio using surface of reliability, density and distribution functions and utility function

(Source: compiled by the authors)

It is obvious that while forming investment strategies in financial markets one should consider many factors influencing the size of investment return and its reliability. Usually to form such strategies stochastic investment networks are being used (Fig. 7).

In order to present the application of the adequate investment portfolio (Rutkauskas 2006; Rutkauskas, Stasytyte 2011a) we will use the task formulated so far in the first chapter of the paper. The problems were analysed showing how to distribute the possessed value among three value fostering possibilities. Three stocks in one portfolio can serve here as these possibilities. The probability distributions defining their powers are also described. The discrete cases of these distributions will be used here. 


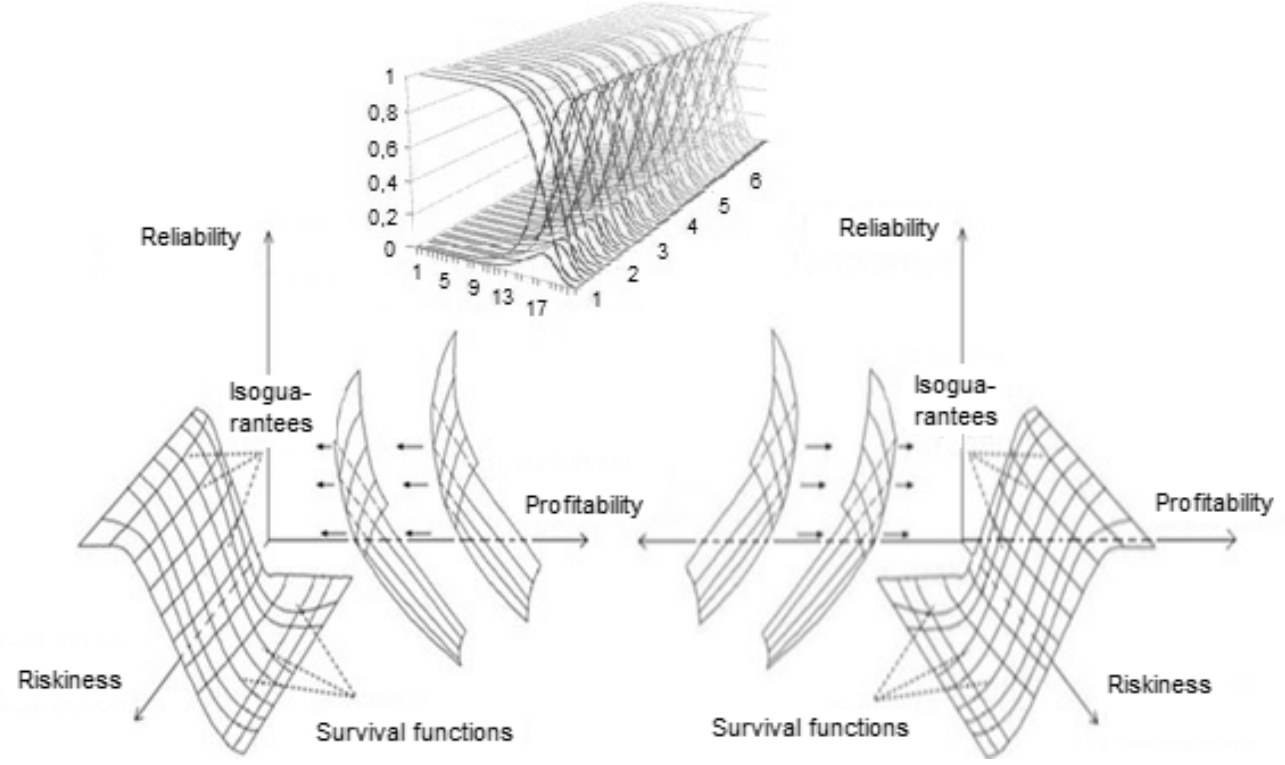

Fig. 7. Investment stochastic network

(Source: compiled by the authors)

The continuous sequence of decision-making is presented in Figure 8 sections $a-f$.
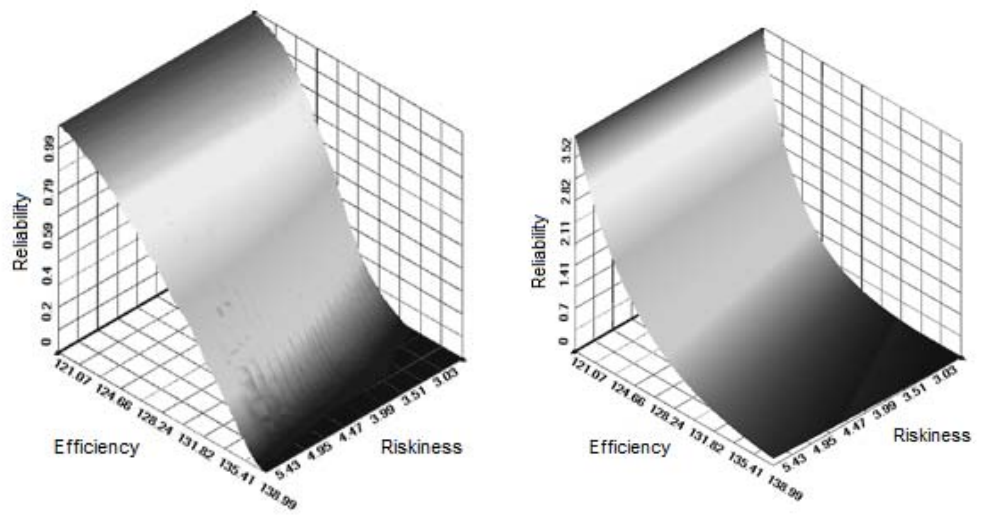

Section a

Section $b$
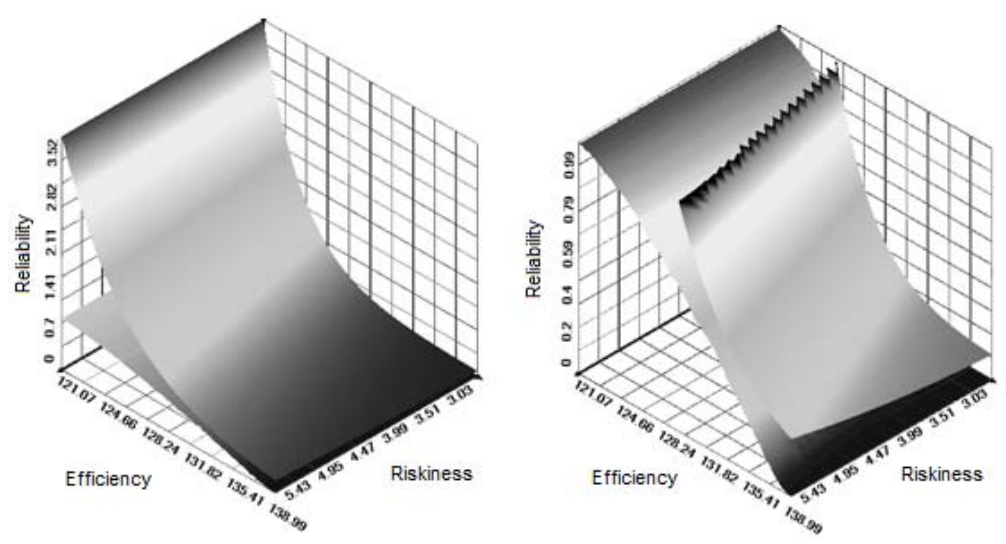

Section c

Section d

Fig. 8. A scheme of decision-making $(\mathrm{a}-\mathrm{d})$ 


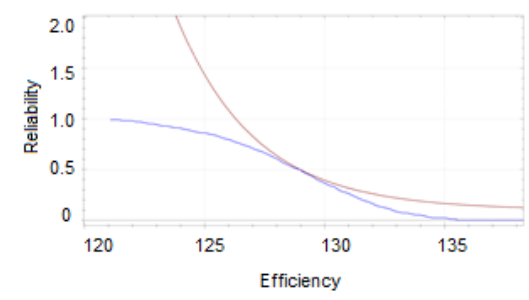

Section e

\begin{tabular}{|l|l|l|}
\hline$w 1$ & $w 2$ & $w 3$ \\
\hline 0.5 & 0.175 & 0.325 \\
\hline$x$ & $P_{x}$ & $D_{x}$ \\
\hline 127 & 0.51 & 3.29 \\
\hline
\end{tabular}

Section $\mathrm{f}$

Fig. 8. A scheme of decision-making (e-f)

(Source: compiled by the authors, based on research results)

Section a presents the so-called surface of possibilities which covers all the points in three-dimensional space "value, reliability of value, level of riskiness".

A note: usually we analyse convex surfaces.

Section $b$ presents the utility surfaces of the certain utility level;

Section c presents the general view of possibility surface and utility;

Section d presents the moment of tangency of the possibility and utility surfaces;

Section e presents the detailed decision-making view;

Section $\mathrm{f}$ shows the coordinates of the solution (tangency point), where $x$ is a value of decision possibility, $P_{x}-$ the reliability of that possibility, $D_{x}$ - the level of possibility riskiness and parameters defining the optimal allocation of resources: $w_{1}, w_{2}, w_{3}$.

\section{Monitoring of the investment system possibilities' adaptivity}

The monitoring of the developed investment system possibilities was performed in different markets and with various investment assets. Here we will briefly show the experimental investment results in DNB Trade virtual platform. Also, backtesting calculations were performed in different markets.

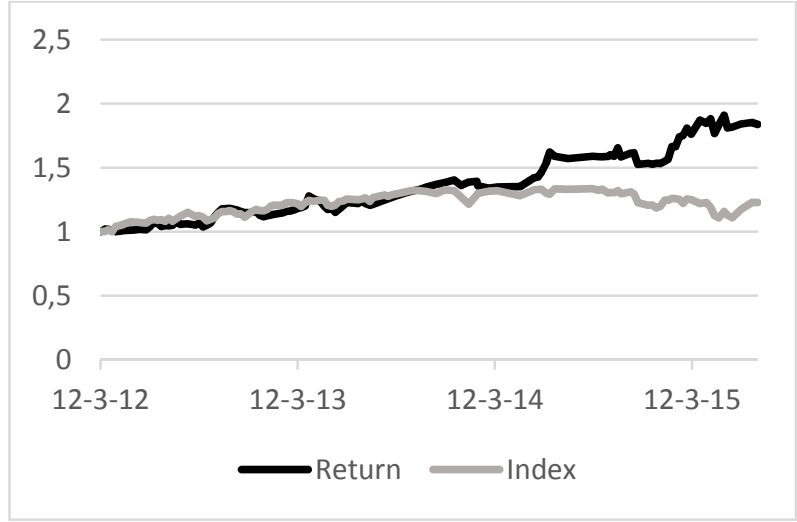

Fig. 9. Investment decisions in NYSE market, using DNB Trade

(Source: compiled by the authors, based on research results)

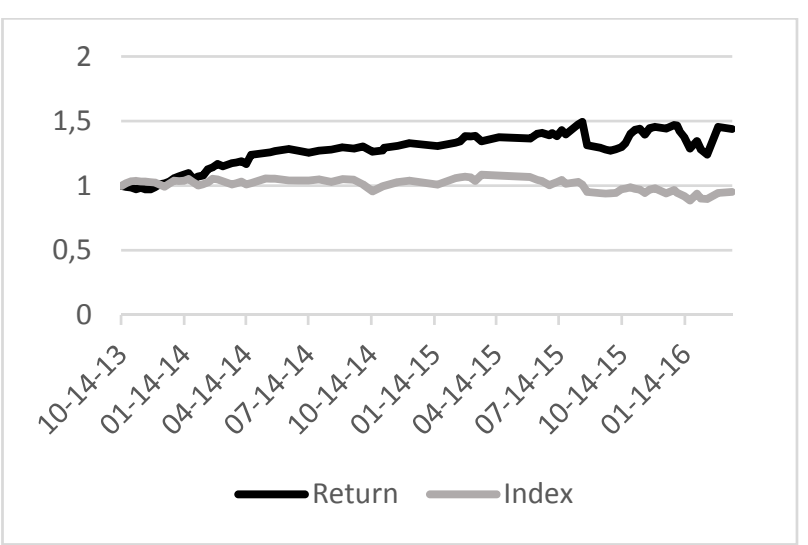

Fig. 10. Investment decisions in UK market, using DNB Trade

(Source: compiled by the authors, based on research results) 


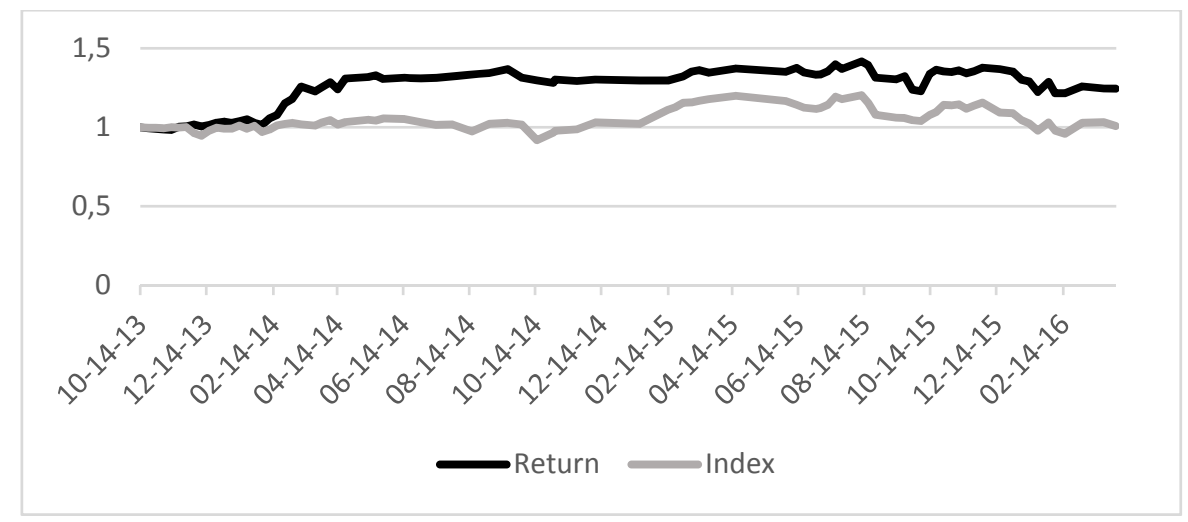

Fig. 11. Investment decisions in France market, using DNB Trade (Source: compiled by the authors, based on research results)

Figures 9-11 show the experimental investment results in NYSE, UK and France market. The axis $x$ represents the growth of the marginal investment unity (starting from 1 at the beginning of investment period), and axis $y$ represents the date. These are results of the continuous four-year investment using the stable methodology during the whole timeperiod (Fig. 9), as well as testing and changing the developed investment strategies (Fig. 10).

\section{Conclusions}

Objectivity and timeliness aspects, along with risk and uncertainty, become more and more important in today's economy and social sciences decisions. The majority of economic decisions, related to financial forecasting and rational resource allocation, are taken under uncertainty. For this reason the stochastic models are used that treat uncertain variables as probability distributions and thus can present the adequate view of future processes.

Sustainable investment strategy in the exchange or capital market can be called a strategy allowing exceeding market generated effect in rather long period. The performed experiments in NYSE, UK and France market, as well as backtesting calculations have confirmed that the developed investment system is capable of reaching the sustainable investment return and can be applied practically. One of the most suitable means for sustainable investment strategy development is adequate investment portfolio.

Adequate investment portfolio can be treated as theoretically sound and practically effective instrument for investment decision-making in capital and currency markets, as well as for other problems related with optimal resource allocation. The adequate portfolio supplements the modern portfolio by adding the third portfolio parameter - the reliability of return. Also, the utility function based on return, reliability and risk is used to find the optimal investment possibility for particular investor.

Along with the reliability of possible values, a key problem of relatively new field - risk economics - is the ability to foster the universally sustainable development and social welfare. The possible integral solutions for these problems can be presented using the adequate portfolio model that allows to allocate rationally the financial resources intended to solve these problems. It also needs to be noted that both presented types of problems in the view of context as well as of transformation are stochastic processes.

Based on the current research presented in the paper, as well as using the results of previous researches, the authors once again confirm the mature thought on reliability as a factor of future value fostering. Using such perception, an attempt could be made to look at the formation of possibilities of country universally sustainable development using the attained objectives, possibilities, extent and the reliability of their transformation in time and to include all of this into the project of fostering the universal sustainability of a country.

\section{References}

Aven, T. 2008. Risk analysis. Assessing uncertainties beyond expected values and probabilities. New Jersey: John Wiley \&Sons. $206 \mathrm{p}$.

Bessler, W.; Wolff, D. 2015. Do commodities add value in multi-asset portfolios? An out-of-sample analysis for different investment strategies, Journal of Banking and Finance 60: 1-20. https://doi.org/10.1016/j.jbankfin.2015.06.021

Boukherroub, T.; LeBel, L.; Ruiz, A. 2017. A framework for sustainable forest resource allocation: a Canadian case study, Omega 66: 224-235. https://doi.org/10.1016/j.omega.2015.10.011

Bruni, R.; Cesarone, F.; Scozzari, A.; Tardella, F. 2017. On exact and approximate stochastic dominance strategies for portfolio selection, European Journal of Operational Research 259(1): 322-329. https://doi.org/10.1016/j.ejor.2016.10.006

Campanale, C.; Fugazza, C.; Gomes, F. 2015. Life-cycle portfolio choice with liquid and illiquid financial assets, Journal of Monetary Economics 71: 67-83. https://doi.org/10.1016/j.jmoneco.2014.11.008 
Campbell, J. Y.; Shiller; R. J. 2007. Robert Shiller interviewed by John Campbell, ch. 11 in P. A. Samuelson, W. A. Barnett, Inside the economist's mind: conversations with eminent economists, Blackwell/Wiley [online], [cited 15 December 2016]. Available from Internet: http://econwpa.repec.org/eps/mhet/papers/0511/0511002.pdf

Chen, T.; He, J.; Li, X. 2017. An evolving network model of credit risk contagion in the financial market, Technological and Economic Development of Economy 23(1): 22-37. https://doi.org/10.3846/20294913.2015.1095808

Chen, Y. Q.; Zhang, S. J. 2014. Risk perception and propensity in bid/no-bid decision-making of construction projects, Engineering, Construction and Architectural Management 22(1): 1-20.

Ching, Y. H.; Colombo, Th. M. 2014. Enterprise risk management good practices and proposal of conceptual framework, Journal of Management Research 6(3): 69-85. https://doi.org/10.5296/jmr.v6i3.5404

Duval, R.; Li, N.; Saraf, R.; Seneviratne, D. 2016. Value-added trade and business cycle synchronization, Journal of International Economics 99: 251-262. https://doi.org/10.1016/j.jinteco.2015.11.001

Fama, E. F. 1991. Efficient capital markets II, Journal of Finance 46: 1575-1618. https://doi.org/10.1111/j.1540-6261.1991.tb04636.x

Fang, L.; Li, H. 2015. Centralized resource allocation based on the cost-revenue analysis, Computers and Industrial Engineering 85: 395-401. https://doi.org/10.1016/j.cie.2015.04.018

Gollier, Ch. 2001. The Economics of risk and time. Cambridge (Mass.): MIT Press. 445 p.

Hirshleifer, J.; Riley, J. G. 1992. The analytics of uncertainty and information. Cambridge University Press. $480 \mathrm{p}$. https://doi.org/10.1017/CBO9781139167635

Iglesias-Casal, A.; López-Penabad, M. C.; López-Andión, C.; Maside-Sanfiz, J. M. 2016. Market perception of bank risk and securitization in Spain, Journal of Business Economics and Management 17(1): 92-108. https://doi.org/10.3846/16111699.2013.807867

Jankauskas, V.; Rudzkis, P.; Kanopka, A. 2014. Risk factors for stakeholders in renewable energy investments, Energetika 60(2): 113-124. https://doi.org/10.6001/energetika.v60i2.2935

Knight, F. H. 1921. Risk, uncertainty, and profit. New York: Houghton and Mifflin. 381 p.

Lapinskaité, I.; Rutkauskas, A. V. 2013. Rinkodaros sąnaudų struktūros optimizavimas kaip verslo plètros tvarumo prielaida, Verslas: teorija ir praktika = Business: Theory and Practice 14(1): 74-82.

Machina, M. J.; Viscusi, W. K. 2014. Handbook of the economics of risk and uncertainty. Oxford: North-Holland. 860 p.

Martinkutė-Kauliené, R. 2014. Risk factors in derivatives markets, Entrepreneurial Business and Economics Review 2(4): 71-83. https://doi.org/10.15678/EBER.2014.020405

Rudzkis, P. 2014. Investiciju ị atsinaujinančiu ištekliu energetika rizikos vertinimas: Daktaro disertacija. Vilnius: Technika. 137 p.

Rutkauskas, A. V. 2006. Adekvačiojo investavimo portfelio anatomija ir sprendimai panaudojant imitacines technologijas, Ekonomika: mokslo darbai 75: 52-76.

Rutkauskas, A. V.; Ostapenko, A. 2016. Return, reliability and risk as a proactive set of concepts in developing an efficient integration strategy of companies, Journal of Business Economics and Management 17(2): 201-214. https://doi.org/10.3846/16111699.2016.1150876

Rutkauskas, A. V.; Stasytyte, V. 2008. Utility function as a constructive instrument for investment decisions making, in The VI International Scientific Conference "Management and Engineering'08”, 19-21 June 2008, Sofia, Bulgaria, 1(104): 217-220.

Rutkauskas, A. V.; Stasytyte, V. 2011a. Optimal portfolio search using efficient surface and three-dimensional utility function, Technological and Economic Development of Economy 17(2): 291-312. https://doi.org/10.3846/20294913.2011.580589

Rutkauskas, A. V.; Stasytytè, V. 2013. Intelligence as a main way to ensure universal sustainability of country's development, Economics and Business: Scientific Journal of RTU 24: 127-134.

Rutkauskas, A. V.; Stasytytė, V.; Michnevič, E. 2014. Universally sustainable development strategy for a small country: a systemic decision, Inžinerine ekonomika 25(5): 530-537.

Rutkauskas, A. V.; Stasytyte, V. 2011b. Markowitz random field as a stand for investment analysis and decision making, in The $15^{\text {th }}$ World Multi-Conference on Systemics, Cybernetics and Informatics: WMSCI 2011, 19-22 July 2011, Orlando, Florida, USA, 131-136.

Samonas, M. 2015. Financial forecasting, analysis, and modelling. A framework for long-term forecasting. UK: John Wiley \& Sons. 215 p.

Song, H.; Ran, L.; Shang, J. 2017. Multi-period optimization with loss-averse customer behavior: joint pricing and inventory decisions with stochastic demand, Expert Systems with Applications 72: 421-429. https://doi.org/10.1016/j.eswa.2016.10.034

Stádník, B.; Raudeliūnienè, J.; Davidavičienè, V. 2016. Fourier analysis for stock price forecasting: assumption and evidence, Journal of Business Economics and Management 17(3): 365-380. https://doi.org/10.3846/16111699.2016.1184180

Steuer, R. E.; Na, P. 2003. Multiple criteria decision making combined with finance: a categorized bibliographical study, European Journal of Operational Research 150: 496-515. https://doi.org/10.1016/S0377-2217(02)00774-9

Taleb, N. N. 2010. The black swan: The impact of the highly improbable. $2^{\text {nd }}$ ed. Random House. 444 p.

Zeng, Y.-R.; Wang, L.; Xu, X.-H. 2017. An integrated model to select an ERP system for Chinese small- and medium-sized enterprise under uncertainty, Technological and Economic Development of Economy 23(1): 38-58. https://doi.org/10.3846/20294913.2015.1072748

Zopounidis, C.; Doumpos, M.; Matsatsinis, N. F. 1997. On the use of knowledge-based decision support systems in financial management: a survey, Decision Support Systems 20: 259-277. https://doi.org/10.1016/S0167-9236(97)00002-X 